\title{
Innovation is vital for elimination of neglected diseases in South Asia
}

\section{Despite some success in reducing the substantial mortality many challenges remain, say Suman Rijal and colleagues}

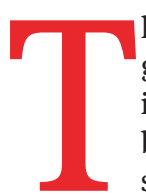
he sustainable development goals set a target to end epidemics of neglected tropical diseases by the year 2030. The task can seem daunting. Equally, having a clear objective can steer global action towards this important health problem that disproportionately affects poor people. The World Health Organization prioritises neglected tropical diseases for control or elimination. Over a billion people worldwide are affected by these diseases, which are seen more commonly in tropical regions.

South Asia has substantial morbidity and mortality associated with infectious diseases, including numerous neglected tropical diseases, and bacterial infections such as neonatal sepsis and enteric fever are of growing concern. Until recently, the Indian subcontinent accounted for $60 \%$ of the global burden of visceral leishmaniasis. ${ }^{1}$ Over $40 \%$ of the global population requiring mass drug administration for lymphatic filariasis elimination is in Bangladesh, India, and Nepal. ${ }^{2}$ The number of people affected by snakebites is also highest in India and Bangaldesh. ${ }^{3}$

This special collection of The BMJ highlights notable successes of public health programmes in neglected diseases in South Asia and identifies areas where research and supportive policy is needed to advance plans for control or elimination. A unifying theme of this collection is innovation in diagnostics, treatment, and prevention of neglected diseases to create solutions that are effective, relevant, locally feasible, and sustainable.

The collection draws on examples of elimination programmes for lymphatic filariasis, visceral leishmaniasis, and snakebite in South Asia. Authors from across South Asia and the world worked

\section{KEY MESSAGES}

- $\mathrm{XXX}$

- $\mathrm{XXX}$

- $\mathrm{XXX}$ together in teams to map the progress in specific disease areas, identify remaining challenges in elimination efforts, and propose solutions to meet this gap. The challenges and strategies on the path to elimination are likely to be similar for other neglected diseases. The articles on typhoid and neonatal sepsis highlight the growing problem of antimicrobial resistance in South Asia, which has greatly limited the available treatment options and leads to treatment failure and higher mortality.

\section{Importance of collaboration}

A few key lessons stand out. Firstly, partnerships and regional collaborations are vital to sustain momentum and foster transfer of knowledge and technology. Driven by a strategic regional collaboration under the kala-azar elimination programme, Nepal and Bangladesh have eliminated visceral leishmaniasis as a public health problem and India has considerably reduced the disease burden. ${ }^{4} \mathrm{~A}$ regional framework such as this can offer a mechanism to address challenges in other disease control programmes. For example, the antivenom used to treat snakebites across South Asia is sourced from India. However, shortages are common, resulting in much higher mortality from snakebites in South Asia than in other areas. Local studies also show the need for antivenoms effective against a wider range of locally prevalent venomous snakes. ${ }^{5}$ Scientists, policy makers, and health professionals must come together to tackle these issues, which cross borders.

A singular focus on disease elimination tends to yield wider action and have a greater impact, as seen with visceral leishmaniasis and lymphatic filariasis. Sri Lanka and the Maldives have successfully eliminated lymphatic filariasis through a combined approach of mass drug administration and robust disease surveillance under the Global Program for Elimination of Lymphatic Filariasis (GPELF). ${ }^{6}$ Over 60\% of the population in endemic areas of South Asia received prophylactic chemotherapy as part of this programme. Political will and continued community ownership will be crucial to successfully eliminate lymphatic filariasis from South Asia.

\section{Need for new treatments}

The strategies have had to evolve to sustain the momentum towards elimination, particularly in larger countries like India. An outlook of fostering continual innovation is critical to meet the changing demands of disease elimination programmes. For example, research conducted by the Drugs for Neglected Diseases initiative in India has shown that post-kala-azar dermal leishmaniasis, a skin condition that occurs in 3-5\% of treated patients with visceral leishmaniasis, may be an important reservoir for transmission, as are patients coinfected with HIV. Current treatment regimens are not optimal for these patients, making sustainable progress towards elimination difficult. New and improved treatments are needed, and for the first time, there is a rich portfolio of oral drug candidates for visceral leishmaniasis, which may result in a new therapy within the next decade. ${ }^{4}$

Similarly, the menace of growing antimicrobial resistance to most firstline drugs for typhoid has given impetus to vaccine discovery. A conjugate typhoid vaccine developed in India has been approved by WHO and is now recommended for routine immunisation of children in endemic countries. ${ }^{7}$

\section{Better systems}

A major challenge in disease control efforts in South Asia is the lack of robust surveillance data. In the absence of an understanding of true disease burden across geographies and changing trends in resistance patterns, it is difficult to design and deliver effective solutions. This is particularly seen with snakebite envenoming, which is a serious public health concern affecting mainly rural and poor populations. It has, however, been neglected until recently because under-reporting and absence of notification and surveillance mechanisms have resulted in a lack of data on its burden. ${ }^{5}$ WHO's recognition of snake- 
bites as a neglected disease by the WHO last year should help drive greater government engagement and regional cooperation to pool together scientific, technological, and financial resources and foster basic research, surveillance, antivenom development, and advocacy.

Disease elimination initiatives tend to function largely as focused vertical programmes, but the need for strengthening health systems in South Asia cannot be overlooked. Deficiencies in availability of drugs, trained staff, critical care support, and transport must be overcome to tackle the high mortality from snakebites, neonatal sepsis, and other diseases in South Asia. A robust primary care network will be important in the post-elimination stages of diseases such as lymphatic filariasis to support surveillance, morbidity management, and disability prevention in those affected. Furthermore, in some areas, population testing and treating may become more cost effective than continuing to scale up mass drug administration. ${ }^{6}$

Antimicrobial stewardship is urgently required across all levels of health facilities, and the paper on neonatal sepsis in this collection offers a simplified model for implementation. ${ }^{8}$ Improved treatment options and standard treatment guidelines are needed to help clinicians and improve outcomes for patients. As part of the Global Antibiotic Research and Development Partnership programme, India is one of 11 countries participating in studies on neonatal sepsis and current antibiotic prescribing practices with the objective of developing improved antibiotic regimens for newborns. The Indian Council of Medical Research is collecting data on antimicrobial resistance from collaborating centres in hospitals across the country part of an Antimicrobial Resistance Surveillance Research Network. The data generated through this network will be useful to monitor trends in resistance and devise treatment guidelines. Similar surveillance mechanisms are needed across the region, alongside studies correlating prescription practices with drug resistance patterns in the community and investigating underlying mechanisms of resistance.

South Asia has a unique role in combating these diseases globally as well as regionally, given the high disease burden and regional expertise in end-to-end solutions, from drug discovery and clinical studies through to regulation, manufacture, and distribution. Such "bench to bedside" leadership could grow rapidly with supportive policy for research and development in neglected diseases. ${ }^{9}$ We are launching this collection at a meeting in New Delhi in January 2019, where stakeholders engaged in neglected diseases control, research, and advocacy in South Asia will come together to celebrate the successes so far and plan for further collaborative action. We call on the diverse communities in the readership of The BMJ to reflect on the issues brought forth in this collection and push for greater action on neglected diseases in their respective fields.

Competing interests: We have read and understood BMJ policy on declaration of interests and have no relevant interests to declare.

Provenance and peer review: Commissioned; not externally peer reviewed.

This article is one of a series commissioned by The $B M J$ in collaboration with the Drugs for Neglected Diseases initiative (DNDi). The $B M$ J retained full editorial control over external peer review, editing, and publication. Open access fees are funded by the DNDi, Geneva.

Suman Rijal, director ${ }^{1}$

Bernard Pécoul, executive director ${ }^{2}$

Balram Bhargava, secretary ${ }^{3}$

${ }^{1}$ Drugs for Neglected Diseases initiative (DNDi), New Delhi, India

${ }^{2}$ DNDi, Geneva, Switzerland
${ }^{3}$ Department of Health Research, Government of India and Director General, Indian Council of Medical Research, New Delhi, India

Correspondence to:SRijal srijal@dndi.org

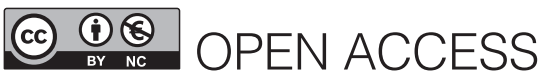

This is an Open Access article distributed in accordance with the Creative Commons Attribution Non Commercial (CC BY-NC 4.0) license, which permits others to distribute, remix, adapt, build upon this work non-commercially, and license their derivative works on different terms, provided the original work is properly cited and the use is non-commercial. See: http://creativecommons.org/licenses/by-nc/4.0/.

\section{Check for updates}

1 Alvar J, Vélez ID, Bern C, et al, WHO Leishmaniasis Control Team. Leishmaniasis worldwide and global estimates of its incidence. PLoS One 2012;7:e35671 doi:10.1371/journal.pone.0035671

2 Global programme to eliminate lymphatic filariasis: progress report, 2015. Wkly Epidemiol $\operatorname{Rec}$ 2016;91:441-55.

3 Kasturiratne A, Wickremasinghe AR, de Silva N, et al. The global burden of snakebite: a literature analysis and modelling based on regional estimates of envenoming and deaths. PLoS Med 2008;5:e218. doi:10.1371/journal.pmed.0050218

4 Rijal S, Sundar S, Mondal D, Das P, Alvar J, Boelaert M. Eliminating visceral leishmaniasis in South Asia: the road ahead. BMJ 2019;364:k5224. doi:10.1136/ bmi.k5224

5 Ralph R, Sharma SK, Faiz MA, et al. The timing is right to end snakebite deaths in South Asia. BM/ 2019;364:k5317. doi:10.1136/bmj.k5317.

6 Specht S, Suma TK, Pedrique B, Hoerauf A. Elimination of lymphatic filariasis in South East Asia. BM/ 2019:364:k5198. doi:10.1136/bmi.k5198.

7 Parry CM, Ribiero I, Walia K, Rupali P, Baker S, Basnyat B. Multidrug resistant enteric fever in South Asia: unmet medical needs and opportunities. BMJ 2019;364:k5322. doi:10.1136/bmj.k5322

8 Chaurasia S, Sivanandan S, Agarwal R, Ellis S, Sharland M, Sankar MJ. Neonatal sepsis in South Asia: huge burden and spiralling antimicrobial resistance. BMJ 2019;364:k5314. doi:10.1136/bmj. k5314

9 Zakir T, Saha GK, Gopakumar KM, Ganguly NK. Can India lead the way in neglected diseases innovation? BM/ 2019:364:k5396. doi:10.1136/bmi.k5396

Cite this as: $B M J$ 2019;364:k5407

http://dx.doi.org/10.1136/bmi.k5407 